\title{
Modeling Characteristics of Chu Teh-chun's Abstract Painting
}

\author{
Feng $\mathrm{Liu}^{1, *}$ \\ ${ }^{1}$ School of Fine Arts, Jiangsu Normal University, Xuzhou, Jiangsu 221116, China \\ "Corresponding author. Email: 923831529@qq.com

\begin{abstract}
This article studies the unique modeling style characteristics of Chu Teh-chun's abstract paintings, and summarizes them into three points: rich and changeable calligraphic style of "points, lines, and surfaces", gentle and solemn unique modeling symbols, and a stable and harmonious modeling relationship construction. Through the summary and analysis of these modeling features, it reflects the painter's pursuit of the spirit of the times, the excavation and innovation of the national cultural traditions, and the thinking and discovery of the essence of art in the exploration of the self-art style of the era.
\end{abstract}

\section{Keywords: Chu Teh-chun, abstract painting, modeling}

\section{INTRODUCTION}

The abstract school is one of the most important schools of Western modern art in the 20th century. It emerged in Europe in the early 20th century. Kandinsky and Mondrian were regarded as pioneers of abstract art. Their art experiments changed the tedious and redundant traditional art pursuit of realism, and refined the pure formal logic language of painting. As a kind of artistic thought and genre concept, abstract painting is opposed to figurative painting. There is no longer any recognizable concrete image on the screen, which is mainly modeled on the plane by points, lines and surfaces. Modeling is not only a means of expression, but also the subject of expression, occupying a very important position. Abstract painters also have distinctive personal style features, such as Kandinsky 's geometric modeling, Mondrian 's checkered modeling, Pollock 's drip painting modeling, Rothko's color gamut flat modeling, etc.

Mr. Chu Teh-chun is the first Chinese academician of French Academie des beaux-arts and a worldrenowned master of abstract painting. He graduated from Hangzhou Art College in his early years, went to France in 1955 to pursue artistic ideals, and was transferred to abstract painting creation under the influence of De Stael. Critics generally believe that his abstract works combine the essence of Eastern and Western paintings, and perfectly integrate the spirit of traditional Chinese painting with the form of Western abstract painting.

What is unique about the modeling process of Chu Teh-chun's abstract paintings? How did he gradually

discover his unique style in artistic practice? This article studies and summarizes these questions.

\section{RICH AND VARIED CALLIGRAPHY STYLE OF "POINTS, LINES, AND SURFACES"}

The rich and varied calligraphic styles of "points, lines, and surfaces" in Chu Teh-chun's paintings are the most obvious characteristics of his personal abstract modeling style. He used the wisdom of Chinese calligraphy to flexibly use a variety of written morphological languages, the flat square brush strokes of clerical script, the circular dot brush strokes of regular script, the delicate and sharp brush strokes of cursive script, etc. The layered calligraphic handwriting effects are interspersed and combined to form a dense and flexible picture. "Points" appear mostly in bright colors in Chu Teh-chun's paintings, and play a finishing touch. They have various characteristics of "points" in Chinese calligraphy, including expression methods such as raising, lowering, turning, lightness, urgency, obliqueness, squareness, and concealment. The "lines" in Chu Teh-chun's lines appear very elegant and beautiful. They have virtual and real, straight and curved lines, large fluctuations, various changes, and a strong sense of rhythm. "Surfaces" are formed by widened "lines" in his paintings, which expand the depth and breadth, express the richness of space, and form a change in light source and shadow between the contrast of light and dark in "surfaces".

The brushstrokes in Chu Teh-chun's paintings are always in a "moving" state. They are used in one stroke at a time, with few traces of modification, revealing the unique spatial expression of Chinese calligraphy. The lines are dignified, soothing, or galloping, just like the 
melody of music, so that the structure of the picture presents a sense of flowing rhythm. This kind of "movement" embodies the "vibrant and vivid" realm pursued by traditional Chinese aesthetics, and its determinant is the inner emotion and life state of the painter when painting. The painter puts on the paintbrush the life state that he has learned in nature, which is endless, wide and broad, and desireless. This is the real theme that Chu Teh-chun 's abstract painting is to convey. It is a means that transcends figurative painting and directly expresses spirit in form. He stands at the critical point of abstraction and figurative haziness, using various calligraphic points, lines, and surfaces as he pleases. This is a high degree of control that has been refined after long-term rigorous training and meticulous thinking. Its freedom on the spiritual level and the naturality of the technique show that Chu Teh-chun's abstract art is inseparable from traditional Chinese calligraphy and painting.

Western abstract expressionist painters often borrowed Chinese calligraphy. After the WWI, Americans first began to study Chinese literature and calligraphy. The American painter Mark Toby traveled to Mexico and the Far East around 1920 and carefully studied Chinese calligraphy and Buddhism Zen. Since 1934, he has introduced Chinese calligraphy skills in paintings. Many powerful and small text symbols have been used on the paintings. In 1957, he created abstract paintings that imitated calligraphy art and oriental paintings, which had a great influence on later Western painters, such as Masson, Klein, and Motherwell. Calligraphic abstraction is also very popular in Europe, and the most influenced by calligraphy are the nonstereotyped schools such as Soulages, Gauthier, Mathieu, and Alepius. However, calligraphy is only a basic training for writing in the West, but it holds a decisive position in China. Western painters attach great importance to the visual effects of the picture. They are difficult to control the movement of the brush and wrist while modeling. It is also impossible for them to have such varied postures and emotions in points, lines, and surfaces, while maintaining the overall sense of the picture during the movement. This is the most basic means of Chinese calligraphy creation. Chu Tehchun said that "Chinese painting has a direct relationship with calligraphy. Westerners do not understand the subtlety of Chinese pens, and they are also very abstract, which is difficult for ordinary people to understand." [1]

The brushes used in Chinese painting are pointed and flexible, with soft and variable thickness, which is a very suitable tool in the tradition of line drawing. The richness of the "lines" expression technique in Chinese painting depends on this special tool, and they way of "using the brush" has also become an important standard for the creation and appreciation of Chinese painters. Shui Tianzhong described Chu Teh-chun's using of the brush as saying: "He used this brush to gallop through the prepared misty space. We can feel the irreplaceable joy of the painter in this unrestrained movement in the traces left by his brush. If the lines in Matthew 's paintings remind people of the pliant forged by the hardness, Chu Teh-chun is really 'indulgent and unrestrained, turning and twisting, up and down, in and out', just like 'waving without sleeve, and circling like the hanging vines'. It is also like 'monkeys running on the tree, fish swimming in the water, troops chasing the enemies, and fire burning the prairie' ( Yu Shinan 'On the Spirit of Pen'). Ancient literati commented on the language of calligraphy is exaggerated and mysterious, but comparing these languages with the lines in Chu Teh-chun's abstract paintings, it is very vivid." [2]

Pierre Cabanna has personally observed Chu Tehchun practicing calligraphy. He described it with a Westerner's vision: "He held the brush straight between his thumb and index finger, letting the little finger control the direction underneath, and relaxed his wrist, which is firm and flexible. Chu Teh-chun has a staggering number of brushes, with strokes of rabbits, wolves, and ferrets, and the barrel is made of bamboo. The brush is a friend and companion of a calligrapher. For the rest of his life, some big calligraphers also asked to be buried with their beloved tools after death. All calligraphers follow these wise advices and write in peace and contemplation. Chu Teh-chun drew inspiration from the poems he wrote, and reconciled his emotional state to express them. Stirring and painint, there are thick ink and light colors. Behavior and attitude are essential. It is because they endow the calligraphy with ever-changing and exquisite and elegant character. The calligrapher should be alone and out of ordinary trivial matters. Therefore, in the past, people were persuaded to get drunk and write ... Zhu called it calligraphy to 'practice his most precise strokes'". He also said: "Any of his paintings are independent in space." This is what Shi Tao called painting in one stroke. Westerners often find it difficult to comprehend the mystery of calligraphy, and only regard it as a wrist gymnastics, but they do not know that it is a kind of asceticism, a ceremonial; it is precisely that it deeply maintains $\mathrm{Chu}$ Teh-chun with his homeland and his tradition." [3] Cabanna believed that calligraphy, as the essence of Chinese plastic art, played an important role in Chu Teh-chun's artistic development. Chu Teh-chun's calligraphy training since his childhood was a superb technique with wisdom and skill, which cultivated delicacy in dexterity and harmony in passion. The important thing in calligraphy is not strokes, but the movement of Chinese characters, liberating the charm, momentum and thoughts in the writing process. [4]

In Chu Teh-chun's 1990 work "Past", it is full of Chinese calligraphic lines. The strokes are gentle, the outlines are drawn, and the flying color blocks are like 
music flowing, light and intoxicating, forming a contrast between static and dynamic in the visual impression. The painter uses the strong contrast of black and white to highlight the smooth use of the main part, and uses the mutual penetration of black, blue and red to highlight a subtle atmosphere. The whole work is intriguing, with a strong contrast and elegant style. The using of brush of calligraphy was used by Chu Tehchun in his works, and the shapes on the screen are directly calligraphy strokes.

\section{GENTLE AND UNIQUE MODELING SYMBOL}

There is also a very obvious visual recognition feature in Chu Teh-chun's paintings, that is, the large brush and the diluted paint are used to move the brush on the paintings, leaving a very wide combination of pen marks on the paintings. When the color and the oil contained are dry, a wonderfully changing edge line is deposited at the edge of the stroke. These heavy and positive brushstrokes on the one hand reflect his high degree of self-confidence and concentration in painting, but also reflect his simple and honest personality. This brush mark effect has become an important formal symbol for recognizing his personal abstract painting language, and it is also the most unique picture mark that distinguishes him from other abstract painters (such as Zao Wou-ki).

When the author visited Mr. Chu Teh-chun in 2005 , he saw a large work in Chu Teh-chun's studio that had just been paved with a large background color, and the large-scale background rendering of the blue background uses this wonderful stroke effect. The author specifically conducted in-depth exchanges with him on this picture effect, confirming that he was inspired by the practice of ink painting, and then constantly experimenting on the special effects summarized on the canvas. In his view, oil painting and ink painting are interlinked. Whether it is Western scraper canvas or Chinese brush and rice paper, what the painter has to do is to use them to describe the picture space and express his true emotions under his familiar cultural background.

In order to achieve this special picture effect, Chu Teh-chun used a wide brush. At first, he himself assembled two brushes with a width of $12 \mathrm{~cm}$ into a super-wide brush. Later, he commissioned the owner of a painting shop to customize a super brush with a width of $25 \mathrm{~cm}$. After the boss put this kind of brush on the shelf casually, it quickly became a hot commodity in the market. Many Paris painters began to try to use this ultra-wide brush. During the author's interview in Paris, he also went to the painting shop that Chu Teh-chun frequently visited, and experienced this wide brush in person. The uniqueness of this large brush lies in the one-time completion method. The traces formed by one stroke cannot be added or modified several times with a small stroke. Zu Wei vividly refers to Chu Teh-chun's special painting method as "surfing" on the canvas, which is the "patent" and recognition feature of Chu Teh-chun's paintings. [5]

In the bright color area in the center of the picture, Chu Teh-chun uses thick pigments with strong covering ability, and depicts various oval "points" at the core position. The edges are treated very softly and moist, forming a bright "gentle" feeling. There are some elegant curves around the points. These lines are also handled very gently. The points and lines together form a rich and delicate tenderness in the bright area.

The vivid and solemn background and the gentle and delicate foreground together form an overall picture, creating a "gentle and sincere" picture effect. Scholar Pan Wan of Taiwan used "Splendid and Glorious" as the title of Chu Teh-chun's album. "Splendid and glorious" is closer to the visual effect, and "gentle and sincere" is the inherent aesthetic connotation.

Chu Teh-chun loves ancient Chinese poetry. The "gentle and sincere" aesthetic effect in his works comes from the advocacy of traditional Chinese aesthetics. "Gentle and sincere, these are the poetry taught us." Education of poetry occupies a very important position in Chinese traditional art education. Chinese traditional aesthetics emphasizes on being "gentle and sincere, sorrow but not hurted", and pursues a "moderate" beauty. In the "Doctrine of the Mean", it is said as: "if there is no expression of happiness, anger, sorrowness or joyment, it is called moderation; when expressing the emotions within the moderation, it is called harmony. Moderation is the base of the world; the harmony is the right way of the world. When realizing the moderation and harmony, the sky and the earth will be in the right position and cultivate everything in the world." $\mathrm{Li}$ Zehou believed that Chinese aesthetics "rejected all kinds of excessively strong sorrow, anger, sad, joy, and various anti-rational displays of lust", which belonged to the "Apollonian" and emphasized "temperance, calmness, reason, and no illusion". It abandoned "fanatic, passionate, fierce, and convulsive emotional catharsis and sensory pleasure", advocated "peace, peace, festival, and degree", and emphasized implicit implicitness and long-term affection. [6]

The emotional expression of traditional Chinese paintings does not promote excessive excitement and enthusiasm, and often favors introverted gentle rationality, which is the implicit and restrained nature after inner cultivation and pursues a quiet beauty. Most Chinese painters are literati themselves, and they attach great importance to reading to "nourish qi". "Qi" is the "temperament" cultivated by painters. The highest standard of Chinese painting is "Yee Pin", which can only be completed by a scholarly painter with a clear mind and a deep learning. In addition to paying 
attention to the beauty of pen and ink, Chinese painting also pays attention to the intangible temperament, education and sentiment, reflected in the tangible image. The process of appreciating painting is an aesthetic process of meditation and tranquility.

\section{CALM AND HARMONIOUS MODELING STRUCTURE RELATIONSHIP}

Careful observing the using of brush in Chu Tehchun's picture, it can be seen that although these strokes are rich and changeable and smooth, they maintain a highly harmonious relationship with the whole painting. Their inclination, shape, and size have been carefully designed and displayed, showing that the painter thought carefully before he began to paint. In the work "Hazy" in 1992, although the white point on the left side of the painting is isolated and eye-catching, it is found that it is very important for the structural balance of the overall picture after careful observation. This is not a rational construction of Western abstract painting, but a natural expression after mastering the principles of picture modeling. Without the profound skills that have been practiced in Chinese calligraphy for a long time, it is simply impossible to cope with such complicated and variable morphological changes. Chu Teh-chun himself said: "I strive to maintain harmony in painting, fineness in roughness, and maintain the overall sense of tranquility."

Desroches, director of the Asian Art Museum of Guimet, France, once observed Chu Teh-chun in his work closely. He said: "I thought he would be quick, just like Zao Wou-ki's using of brush. However, Chu Teh-chun has no speed at all. He may throw three or four points very quickly at first, but the process may end in 5 minutes. Next, he will take a few steps back, and then a few steps forward, adding a stroke silently. A work often takes up to several weeks." What impressed Desroches the most was the quietness of Chu Teh-chun: "He works like a monk, very quiet and very slow, like finding points on acupuncture." [7] Although his works convey a wide-open and unrestrained atmosphere, Desroches pointed out his working process like the meditating old monk. From this, people can see the true side of Chu Teh-chun's painting, which is a highly concentrated and focused state. Van Gogh once described a similar state of painting: "You have to know that I am in the most complicated calculation. From this one painting after another, it was completed very quickly, but after a long period of preliminary preparation, One must think of thousands of things in half an hour, like a logician, who can track balance and color calculations and repeated calculations." [8] As a bystander, what may be seen is the seeming calmness in the painter's creative process. Under this calmness, it is hided with the painter's highly complex mental activities.
Inspired by De Stael's "freedom", Chu Teh-chun gave up the figurative depiction. He hoped to get rid of the object image and enter the "invisible" selfexpression stage of abstract art. In the earliest abstract experiments, he still needed the help of cities, human bodies and flowers to get the most basic picture and color feelings. In order to reach a more "pure" abstraction, Chu Teh-chun turned to the structuralist construction method and entered the stage of pure geometric abstract structure. The thick black lines become the main body of the structure of the picture. Although a little color in the background still implies the existence of the landscape, his attention has been completely focused on the abstract formal language research of the body of the painting. This stage lasted for several years. From a large number of exploration works, it can be seen that his painting state was restrained at the time and his creative thinking was blocked, but this stage is also when he has benefited most from Western modern art, such as the meaning of points, lines, and faces in abstract structures, the relationship and organization of modeling structures, the expressiveness of colors and spatial expression, etc., all of which are the most basic problems in modern painting after the stripping of specific images. Later, he talked about Kandinsky's influence several times in the interview. It can be seen that he had worked hard on the formal language of modern art. In a nutshell, if it did not go through this long period of rational and rigorous gestation, there would be no free-spiritedness that he later mastered on the canvas. By deeply absorbing the latest research results of Western abstract paintings on the art noumenon, while building a solid modeling relationship in the picture, he deeply penetrates the internal principles of things through appearances, and directly expresses his feelings on the charm, artistic conception, life spirit, etc., building a free expression channel between the subjects and objects. In this regard, he expressed: "I think the painter should create on the basis of studying Chinese culture and Western culture, and don't clinch. The real fusion is the fusion of Eastern and Western ideas, which are naturally and invisibly revealed in the work, otherwise it can only be pieced together." He once used the inextricable mixture of coffee and milk as a metaphor for the deep integration of Chinese and Western cultures. His painting creation comes from a deep understanding of Eastern and Western cultures, and the fusion of content and form is rooted in the deep soil of two different cultures.

\section{Conclusion}

From the above summary, it can be seen that through years of artistic exploration, Mr. Chu Teh-chun has found his own unique expression in the modeling of abstract painting. He first delved into the construction methods of Western abstract paintings, drawing on the essence of modern painting forms; Then, through the 
bypass of calligraphy training, it changed the rigidity of western abstract modeling, forming a vivid and smooth way of using pens and rich and varied calligraphic style of "points, lines, and surfaces"; At the same time, he continued to refine and summarize in his painting practice, and found his own "gentle and sincere" unique modeling symbol. Mr. Chu Teh-chun has been diligent all his life, focusing on the pursuit of art. His experience and efforts in dealing with the combination of the spirit of the times and traditional art, blending Chinese and Western paintings, and searching for his own artistic style are worthy of people's deep consideration.

\section{References}

[1] Xing Xiaozhou, Xing Xiaozhou Interview [M]. Chu Teh-chun Art Exhibition. Guangzhou: Guangdong Museum of Art, 2000: 29, 26. (in Chinese)

[2] Shui Tianzhong, Looking at the New Work by Chu Teh-chun [N]. Guangming Daily, 1997-06-01. (in Chinese)

[3] (France) Pierre Cabanna, Chu Teh-chun [M]. Beijing: SDX Joint Publishing Company, 2000: 33.

[4] (France) Pierre Cabanna, Chu Teh-chun's Painting: Expressing the Heart and Nature [M]. Chu Teh-chun Art Exhibition. Guangzhou: Guangdong Museum of Art, 2000: 18.

[5] Zu Wei, Biography of Chu Teh-chun [M]. Shanghai: Wenhui Press, 2001: 157. (in Chinese)

[6] Wang Ping, A Comparative Study of Chinese and Western Cultural Aesthetics [M]. Hangzhou: Zhejiang Gongshang University Press, 2010: 40. (in Chinese)

[7] Du Ka, Enduring Chinese Art of the 20th Century [J]. Xiamen Airlines: 2010. 10. 01. (in Chinese)

[8] Ye Jianqing, Oil Painting Technique Tutorial [M]. Tianjin: Tianjin People's Fine Arts Publishing House, 2001: 04. (in Chinese) 